\title{
18. Growth, Structural Change and Productivity Gaps in China's Industrial Sector
}

Yanrui Wu, Ning Ma and Xiumei Guo

China's high economic growth in recent decades has been associated with rapid industrialisation; however, there are considerable regional variations in industrial development in the country. Several authors have provided empirical evidence of possible regional convergence in recent decades (Wang and Szirmai 2013; Rizov and Zhang 2014; Lemoine et al. 2014). Wang and Szirmai (2013) considered provincial industrial labour productivity and found regional evidence of convergence in the 1980s and 2000s. Rizov and Zhang (2014) employed micro-level data to show that the density of economic activity, economic policy and structural factors have affected regional productivity levels and growth differentials. Lemoine et al. (2014) argued that China's interior regions are catching up with more developed coastal areas in terms of labour productivity levels and hence the country is becoming more integrated technologically. This study adds to the existing literature. Its objective is to present a shift-share analysis of productivity gaps in industrial sectors across Chinese regions. For this purpose, a review of China's industrial growth in recent years is presented first. Then an assessment of possible structural change in the industrial sector is provided. This is followed by the analysis of labour productivity gaps across regions. The main findings are summarised in the concluding section.

\section{Industrial growth and analysis}

Figure 18.1 shows the contributions of agriculture, industry and services to GDP growth over time. It is apparent that the industry has the largest share among the three sectors. This share has, however, shown a declining trend in recent years. This phenomenon may reflect the country's policy shift to promote consumption-driven economic growth. After three decades of high growth, the Chinese economy is now in the process of transformation from being labour intensive to innovation oriented, and from being overly dependent on investment to greater reliance on domestic demand. The industrial sector is changing in response to ongoing macro-economic adjustment. This section provides a brief review of recent trends and developments in the industrial sector. 


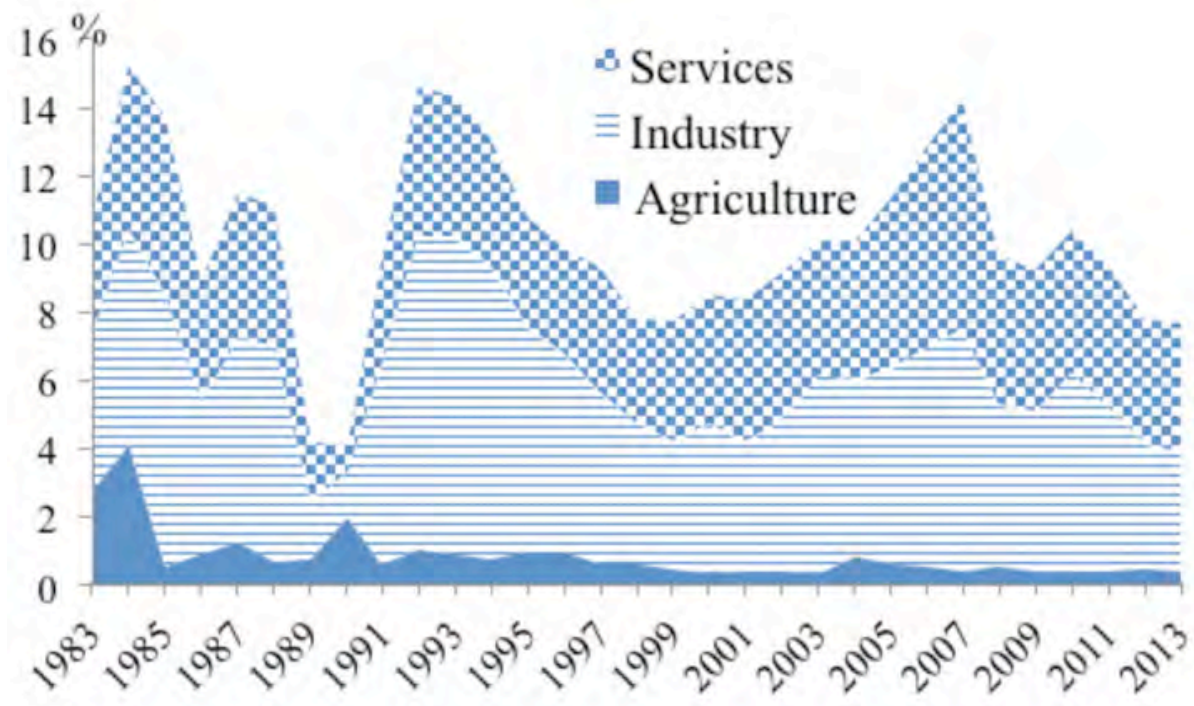

Figure 18.1 Contribution to Economic Growth by Sector, 1983-2013 Source: Authors' calculations using statistics from NBS (various years).

Table 18.1 presents the average growth rates of industrial output in selected subsectors in China. All subsectors experienced high growth during the period 1994-2010, which corresponds with the deepening of economic reforms after Deng Xiaoping's 1992 tour of southern China. Growth in the 2000s (with an average rate of 21.2 per cent during 2001-10) was much faster than that in the 1990s (with an average rate of 9.9 per cent during 1994-2000). This difference may be due to two factors. First, growth in the 1990s was interrupted by the 1997 Asian financial crisis. Second, China's accession into the World Trade Organisation (WTO) in 2001 stimulated the country's export sector. Industry groups with above average growth for the period 2001-10 include pharmaceuticals, non-metallic minerals, smelting and processing of ferrous and nonferrous metals, general and special-purpose machinery, transportation, electrical and telecommunications equipment, and instruments and meters. In particular, the six sectors at the bottom of the list in Table 18.1 exhibited the highest growth. These sectors mainly cover industries embodying relatively high technology (transport, electrical and communication equipment, and measuring instruments), which enjoyed an export boom after China became a WTO member in 2001. 
Table 18.1 Average Growth Rates of Industrial Output by Sector (per cent)

\begin{tabular}{|l|c|c|c|c|}
\hline Sectors & $\mathbf{1 9 9 4 - 0 0}$ & $\mathbf{2 0 0 1 - 0 5}$ & $\mathbf{2 0 0 6 - 1 0}$ & $\mathbf{2 0 0 1 - 1 0}$ \\
\hline Food processing & 4.1 & 19.9 & 20.1 & 20.0 \\
\hline Food manufacturing & 0.8 & 20.8 & 20.8 & 20.8 \\
\hline Beverages & 13.4 & 11.9 & 22.2 & 17.0 \\
\hline Tobacco & 8.0 & 12.8 & 15.0 & 13.9 \\
\hline Textiles & 2.6 & 19.7 & 15.2 & 17.4 \\
\hline Paper and paper products & 6.8 & 22.5 & 19.1 & 20.8 \\
\hline Petroleum & 2.6 & 12.4 & 8.9 & 10.6 \\
\hline Chemical products & 9.7 & 19.1 & 21.7 & 20.4 \\
\hline Pharmaceuticals & 5.0 & 24.2 & 20.7 & 22.4 \\
\hline Chemical fibres & 8.8 & 15.0 & 12.6 & 13.8 \\
\hline Nonmetallic products & 6.7 & 20.1 & 25.3 & 22.7 \\
\hline Ferrous metals & 1.1 & 28.4 & 16.8 & 22.6 \\
\hline Nonferrous metals & 9.0 & 24.3 & 21.9 & 23.1 \\
\hline Metal products & 12.2 & 19.2 & 23.3 & 21.2 \\
\hline General purpose machinery & 21.2 & 28.7 & 26.0 & 27.3 \\
\hline Special purpose machinery & 10.4 & 22.8 & 27.1 & 25.0 \\
\hline Transport equipment & 11.7 & 27.0 & 28.4 & 27.7 \\
\hline Electrical equipment & 14.9 & 25.5 & 23.2 & 24.3 \\
\hline Communication equipment & 28.7 & 38.1 & 18.8 & 28.4 \\
\hline Measuring instruments & 31.1 & 19.3 & 25.2 \\
\hline
\end{tabular}

Sources: Authors' calculations using data from China Statistical Yearbook (NBS various years) and China Statistical Yearbook of Industrial Economy (NBS various years).

At the regional level, China's regions experienced remarkable growth in industrial output 1994-2010 (Table 18.2). ${ }^{1}$ Consistent with the growth trend at the sectoral level, regional growth in the 2000s was much faster than that in the 1990s. In addition, average growth in the coastal area (coded number 1 in Table 18.2) was much higher than that in the rest of the country. This trend was maintained in the early 2000s. In the second half of the 2000s, however, industrial growth in the non-coastal areas exceeded that in the coastal areas. Several policy changes might be responsible for the catch-up of the non-coastal areas. These include the implementation of the western development program in 1999, the north-east regional reinvigoration program in 2003 and the 'middle region rise' strategy in 2006. In Table 18.2, the middle, western and north-east regions are coded 2, 3 and 4, respectively. On average, the annual growth rate during 2006-10 was 17.6 per cent for the coastal group, 26.3 per cent for the middle regions and 21.1 per cent for both the western regions and the three north-eastern provinces.

1 Tibet is excluded due to missing data. 
Deepening Reform for China's Long-Term Growth and Development

Table 18.2 Average Growth Rates of Industrial Output by Region (per cent)

\begin{tabular}{|c|c|c|c|c|c|}
\hline Code & Region & 1994-00 & 2001-05 & 2006-10 & $2001-10$ \\
\hline 1 & Beijing & 6.0 & 20.7 & 10.9 & 15.8 \\
\hline 1 & Tianjin & 7.7 & 21.8 & 17.8 & 19.8 \\
\hline 1 & Hebei & 8.7 & 22.6 & 19.3 & 20.9 \\
\hline 1 & Shanghai & 6.5 & 21.2 & 13.7 & 17.4 \\
\hline 1 & Jiangsu & 8.4 & 24.9 & 21.7 & 23.3 \\
\hline 1 & Zhejiang & 10.8 & 27.1 & 16.0 & 21.5 \\
\hline 1 & Fujian & 9.6 & 25.5 & 20.8 & 23.1 \\
\hline 1 & Shandong & 10.9 & 28.5 & 20.0 & 24.2 \\
\hline 1 & Guangdong & 10.7 & 25.6 & 18.2 & 21.9 \\
\hline 2 & Shanxi & 8.2 & 19.0 & 17.7 & 18.4 \\
\hline 2 & Anhui & 3.2 & 19.0 & 29.1 & 24.0 \\
\hline 2 & Jiangxi & 3.2 & 21.4 & 31.8 & 26.6 \\
\hline 2 & Henan & 10.5 & 20.7 & 24.3 & 22.5 \\
\hline 2 & Hubei & 6.2 & 12.2 & 26.9 & 19.5 \\
\hline 2 & Hunan & 3.9 & 19.9 & 28.0 & 24.0 \\
\hline 3 & Hainan & 4.8 & 15.5 & 26.9 & 21.2 \\
\hline 3 & Inner Mongolia & 4.2 & 29.4 & 26.6 & 28.0 \\
\hline 3 & Guangxi & 3.4 & 17.4 & 25.4 & 21.4 \\
\hline 3 & Chongqing & 11.6 & 22.0 & 26.6 & 24.3 \\
\hline 3 & Sichuan & -1.2 & 22.0 & 26.3 & 24.2 \\
\hline 3 & Guizhou & 9.5 & 15.3 & 13.4 & 14.4 \\
\hline 3 & Yunnan & 6.6 & 16.5 & 15.7 & 16.1 \\
\hline 3 & Shaanxi & 6.7 & 18.3 & 23.1 & 20.7 \\
\hline 3 & Gansu & 4.1 & 15.9 & 13.9 & 14.9 \\
\hline 3 & Qinghai & 6.3 & 14.5 & 24.3 & 19.4 \\
\hline 3 & Ningxia & 5.1 & 20.5 & 18.7 & 19.6 \\
\hline 3 & Xinjiang & 9.4 & 13.4 & 18.0 & 15.7 \\
\hline 4 & Liaoning & 1.8 & 17.9 & 23.6 & 20.8 \\
\hline 4 & Jilin & 7.0 & 15.8 & 26.4 & 21.1 \\
\hline 4 & Heilongjiang & 3.1 & 10.7 & 13.4 & 12.0 \\
\hline
\end{tabular}

Sources: Authors' calculations using data from China Statistical Yearbook (NBS various years) and China Statistical Yearbook of Industrial Economy (NBS various years).

\section{Industrial growth analysis}

Numerous studies on industrial growth, structural change and productivity analysis have focused on Asian, European and North American regions. Esteban (2000) used the standard shift-share analysis to decompose regional productivity gaps relative to the European average into three components-industry mix, 
regional components and allocative components. Esteban's results reveal that inter-regional differences can be almost fully explained by region-specific productivity inequality. Thus, from a policy perspective, in order to close the gap between advanced and less-developed regions, economic policies should focus on factors affecting the productivity of backward regions. Somewhat similar to Esteban (2000), Fiaschi and Lavezzi (2007) examined sectoral contributions to aggregate growth in European regions during the period 1980-2002 by decomposing the average growth rate into two components - the productivity growth effect (PGE) and the share effect (SE). Their results illustrated that the contribution of PGE to overall growth is remarkably large relative to that of SE. The growth rate is therefore almost completely attributable to technological changes within sectors. The PGE mainly benefits from the increase in productivity in manufacturing, mining, agriculture and transportation, while the other market service sector suffers from a fall in productivity over the period. SE benefits from the contribution of the other market service and non-market service sectors but this benefit is almost offset by the negative contributions of the agricultural, manufacturing and mining sectors. Overall, other market service, manufacturing, non-market service, wholesale and retail, and transportation are the sectors with the greatest contributions to productivity growth.

Furthermore, Benito and Ezcurra (2005) applied non-parametric techniques to examine the evolution of the distribution of regional productivity in the European Union between 1977 and 1999. Their method involves the shift-share analysis. They argued that there are clear spatial links as neighbouring regions of the European Union are found to share a similar pattern of labour productivity. Moreover, regions with relatively low and medium labour productivity have a greater tendency towards geographical clustering than regions with high labour productivity. They also found that the industry mix contributed relatively little to regional dispersion in the European Union. The main factors determining regional inequality in productivity would be basically those that have a uniform effect on productivity in all sectors (Benito and Ezcurra 2005). The structural component appeared to have played a minor role in regional inequality during the period covered.

Kallioras and Petrakos (2010) calculated the coefficient of structural change (CSC) and the index of dissimilarity of industrial structures (IDIS) for regions within the EU new member states (EU NMS) during the period 1991-2000. Their results revealed that each EU NMS region experienced its own level of structural adjustment. While the majority of the regions of the more advanced EU NMS (including Slovenia, Hungary and Estonia) tend to show a low degree of structural change, most of the less-advanced regions (such as Bulgaria and Romania) show a high degree of change. In addition, the estimated IDIS values show that most of the Bulgarian and Romanian regions have increased 
their dissimilarity (Kallioras and Petrakos 2010). Almon and Tang (2011) used a decomposition technique to determine the contribution of each industry to economic growth in Canada and the United States. They found that the manufacturing sector was the main source of the post-2000 slowdown in labour productivity in Canada and it continued to contribute less to aggregate growth than in the United States. Their results indicated that the manufacturing sector in both Canada and the United States was adversely affected by structural change during the period 2000-08.

Timmer and Szirmai (2000) also investigated productivity growth by using shift-share analysis. They used four Asian countries as their case study and found that resource allocation did not make extra contributions to aggregate productivity growth, in addition to growth in individual sectors. They hence argued that manufacturing sector-wide effects on productivity growth are more important than industry-specific effects in rapidly growing developing countries. This argument is consistent with theories of conditional convergence, which stress the importance of economy-wide factors for growth. These factors include innovation, the provision of financial and business services, development of an extensive physical infrastructure and high investment ratios (Abramovitz 1989; Timmer and Szirmai 2000).

\section{Studies of Chinese industries}

The papers reviewed in the preceding section are mainly concerned with developed economies partly because of the abundance of data for these countries. Recently a number of scholars have also investigated industrial structural change in China. For example, O'Callaghan and Yue (2000) found that Chinese industrial sectors including freight transport, petroleum and natural gas production and other mining industries were responsible for more than 50 per cent of overall structural change between 1987 and 1995. Many scholars have also examined factors that affect industrial structure. For example, Chen and Wu (2003) focused on technology, innovations and foreign direct investment (FDI), while Li and Long (2001) focused on consumption structure. Wen (2004) examined industrial clustering and illustrated that Chinese manufacturing industries became increasingly geographically concentrated. Based on the analysis of a panel dataset of 32 industries in 29 regions, Bai et al. (2004) found that the geographic concentration of industrial production increased between 1984 and 1997. Fan and Scott (2003) provided evidence to support the existence of a positive relationship between industrial clustering and productivity growth. They also argued that China's economic reform has a positive impact on macroeconomic and local conditions under which industrial clustering can emerge. 
China's robust economic performance is not only due to the accumulation of physical capital and conditional convergence, but also to the improvements in factor productivity through structural change (Xu and Voon 2003). Many discussions of China's industrial performance have focused on the differences in productivity between the coastal and inland regions. Using a balanced panel dataset covering more than 250000 'above designated size' enterprises, Jefferson et al. (2008) found significant productivity variation among the firms across the regions between 1998 and 2005. The authors also provided evidence of partial catch-up, particularly for the central region. They argued that much of the catch-up reflects the relative backwardness of firms outside the coastal regions. Their results also showed that productivity growth in the inland regions remains the same as or lower than that of the coastal region, thereby barring the firms in central and western China from the opportunity of achieving productivity parity with their coastal counterparts. Moreover, they found that by 2005, the industrial productivity gap between China's central and coastal regions had narrowed substantially, while the productivity levels of the west and north-east, respectively, rose to 83 per cent and 85 per cent of that of the coast.

Dong et al. (2011) used panel data from 31 provinces spanning three decades and examined the relationship between economic growth and industrial structure. They concluded that short-run economic fluctuation could cause industrial structural imbalance while a long-run bi-directional causal relationship exists between industrial structural imbalance and economic fluctuation. Using regression analysis, they found that per capita GDP, domestic consumption, income inequality, labour force and capital stock are important determinants of China's industrial structure. Their empirical evidence confirms that a long-term relationship exists between industrial structure and economic growth, and that domestic consumption also significantly affects China's industrial structure.

Marti et al. (2011) investigated the effect of China's WTO membership on regional industrial productivity. They found that China's central zone recorded the largest increase in industrial productivity during the period 1995-2006; however, practically all regions have improved remarkably as a result of China becoming a member of the WTO. Overall growth in productivity has been driven by the enhancement of technology. Therefore, as illustrated by the results of technical efficiency estimates, more emphasis should be placed on using inputs more efficiently. Moreover, convergence results do not reveal great changes in the country as a whole post 2001. Existing regional differences in terms of industrial value added are, however, seen to have decreased slightly due to the western regions developing more rapidly (Marti et al. 2011). 
Lin et al. (2011) provided evidence of positive correlation between industrial clustering and productivity. They argued the Government should continue to implement its industrial park policy and hence create agglomerations of high-technology firms with positive externalities that can enhance firm-level productivity. Small firms established in clustered regions could benefit more than large firms from the positive externalities of agglomeration. Such positive externalities are associated with information sharing, greater ease in finding professionals, the savings from lower transportation costs, and so on. Thus, the Government could more actively promote industrial zones for small firms in order to help them improve their productivity and development. In addition, foreign enterprises have the highest productivity, followed in turn by the private enterprises and state-owned enterprises (SOEs). Therefore, there is room for productivity improvement in private enterprises. Furthermore, the Government should continue the course of SOE restructuring to strengthen management and productive efficiency (Lin et al. 2011).

Furthermore, Wei(2000) argued that regional spillover effects may be sufficient to reduce inequality in the regions of China. The tests for inter-regional spillover effects indicate that output growth in the coastal zone spills over into the growth of the central and western zones and that the central zone's growth also affects the western zone's development (Zhang and Felmingham 2002). More recently, Peng and Hong (2013) explored productivity spillovers among linked sectors. They argued that productivity in a sector is determined not only by production factors such as labour and capital but also by spillovers from linked sectors. One of the spillovers - namely, the knowledge spillover among sectors - could lead to cost reduction. Peng and Hong adopted the concept of economic distance to measure intersectoral linkages. They concluded that economic distance plays a more important role than spatial distance in transmitting productivity spillover.

The above-surveyed studies have contributed to the understanding of industrial development, structural change and productivity growth in China; however, most of the studies have analysed data either for a limited time span or at a highly aggregated level. This study adds to the existing literature by exploring sectoral data within each region in China.

\section{Structural change in the industrial sector}

To analyse the pattern and changes of industrial structure in China's regions during 2000-10, the coefficient of structural change (CSC) is estimated. Havlik (1995) stated that the CSC correlates the shares (S) of each sector $i(i=1,2 \ldots \mathrm{n})$ in region $r$ between an initial year, $\mathrm{t}$, and an end year, $t+k$. Symbolically, the CSC can be expressed as Equation 18.1. 
Equation 18.1

$$
\operatorname{CSC}_{r, t_{-} t+k}=\operatorname{CORREL}_{i=1}^{n}\left(S_{r, i, t}, S_{r, i, t+k}\right)
$$

In Equation 18.1, CSC takes values in the interval [0, 1]. Values close to zero indicate that significant structural changes have taken place during the period between $t$ and $t+k$, whereas values close to 1 indicate that almost no structural change has taken place. The shares can be based on either output or employment across the regions.

The data used in this study are collected from China's official statistical resources, and the sample covers 2000-10, 20 manufacturing subsectors and 30 Chinese regions. According to Tables 18.3 and 18.4, some regions experienced more structural change while others demonstrated very little variation over time. At the national level, structural change was modest during 2000-10. Among the regions, Hunan and Hainan have the lowest CSC scores between 2000 and 2010, implying the most structural change recorded among the regions. Within the 10 best-performing regions, seven show more structural change in the second half of the decade (Table 18.3). Regions with the least change in their CSC scores include Fujian, Guangdong and Chongqing. Eight of the 10 regions with the least structural change between 2000 and 2010 have CSC scores above 0.90 (Table 18.4). Tables 18.3 and 18.4 also show that there is no clear distinction between the coastal and interior regions in terms of structural change. The results using employment shares are not reported and show similar patterns.

Table 18.3 Regions with More Structural Change

\begin{tabular}{|l|c|c|c|}
\hline Regions & $\mathbf{2 0 0 0 - 0 5}$ & $\mathbf{2 0 0 5 - 1 0}$ & $\mathbf{2 0 0 0 - 1 0}$ \\
\hline National & 0.91 & 0.96 & 0.86 \\
\hline Liaoning & 0.92 & 0.72 & 0.54 \\
\hline Heilongjiang & 0.88 & 0.82 & 0.57 \\
\hline Jiangsu & 0.81 & 0.96 & 0.71 \\
\hline Anhui & 0.84 & 0.92 & 0.69 \\
\hline Jiangxi & 0.91 & 0.77 & 0.62 \\
\hline Shandong & 0.91 & 0.87 & 0.68 \\
\hline Hunan & 0.87 & 0.67 & 0.43 \\
\hline Guangxi & 0.83 & 0.95 & 0.68 \\
\hline Hainan & 0.70 & 0.49 & 0.34 \\
\hline Shaanxi & 0.88 & 0.89 & 0.66 \\
\hline
\end{tabular}

Sources: Authors' calculations using data from China Statistical Yearbook (NBS various years) and China Statistical Yearbook of Industrial Economy (NBS various years). 
Deepening Reform for China's Long-Term Growth and Development

Table 18.4 Regions with Less Structural Change

\begin{tabular}{|l|c|c|c|}
\hline Regions & $\mathbf{2 0 0 0 - 0 5}$ & $\mathbf{2 0 0 5 - 1 0}$ & $\mathbf{2 0 0 0 - 1 0 ~}$ \\
\hline National & 0.91 & 0.96 & 0.86 \\
\hline Hebei & 0.93 & 0.98 & 0.90 \\
\hline Shanxi & 0.95 & 0.97 & 0.92 \\
\hline Inner Mongolia & 0.88 & 0.84 & 0.75 \\
\hline Jilin & 0.97 & 0.99 & 0.94 \\
\hline Fujian & 0.98 & 0.99 & 0.97 \\
\hline Guangdong & 0.97 & 1.00 & 0.96 \\
\hline Chongqing & 0.99 & 1.00 & 0.98 \\
\hline Yunnan & 0.98 & 0.98 & 0.92 \\
\hline Oinghai & 0.98 & 0.96 & 0.94 \\
\hline Xinjiang & 0.96 & 0.87 & 0.76 \\
\hline
\end{tabular}

Sources: Authors' calculations using data from China Statistical Yearbook (NBS various years) and China Statistical Yearbook of Industrial Economy (NBS various years).

A further assessment of the nature of the industrial structural patterns in China's regions can be conducted through the estimation of the index of dissimilarity of industrial structures (IDIS). The IDIS is defined as the sum of the square of the difference between the share $(\mathrm{S})$ of sector $i(=1,2 \ldots, \mathrm{n})$ in region $r$ and the share in a benchmark economy $b$ in a given year, $t$ (Kallioras and Petrakos 2010). In mathematical form this is Equation 18.2.

Equation 18.2

$$
I D I S_{r_{-} b, t}=\sum_{i=1}^{n}\left(S_{r, i, t}-S_{b, i, t}\right)^{2}
$$

Here the average share of each sector across the region is used as the benchmark score. The IDIS takes values greater than (or equal to) zero. High values imply high levels of structural dissimilarity with the national average, whereas low values indicate low levels of structural dissimilarity. Increasing values of the IDIS indicate that the regions under consideration are becoming more dissimilar, whereas decreasing values imply that the corresponding regions are becoming more similar. In the cases of less-developed regions, increasing structural dissimilarity is an indication of a negative (defensive) structural change, whereas decreasing structural dissimilarity is an indication of a positive (offensive) structural change. Defensive structural changes can be noticed as impulsive reactions to the conditions and requirements of an emerging economic environment whereas, offensive structural changes can be seen as strategic choices (Kallioras and Petrakos 2010). 
In general the estimated IDIS values in terms of industrial output for each region during 2000-10 are very low, ranging from the lowest of 0.002 to the highest of 0.223 . These values indicate low levels of structural dissimilarity among the Chinese regions. Yunnan, Chongqing and Jilin recorded relatively high IDIS scores over time. Thus these regions have an industrial structure with high dissimilarity with the national average structure. To make interpretation easy, the average scores for 2000-04 and 2006-10 for each region are computed and compared. Three regions with the greatest increase in IDIS scores (defensive structural change) are Hebei, Shanghai and Guangdong, which all are coastal regions (Table 18.5). Seven regions-namely, Yunnan, Jilin, Qinghai, Tianjin, Inner Mongolia, Ningxia and Hainan - show decreased dissimilarity with the benchmark average structure. This implies that these regions experienced intraindustry types of economic integration and most likely undertook offensive structural changes between 2000 and 2010 .

Table 18.5 Regions with the Most Structural Changes

\begin{tabular}{|l|c|c|c|}
\hline Regions & 2000-04 & 2006-10 & Changes \\
\hline & \multicolumn{3}{|c|}{ Defensive } \\
\hline Hebei & 0.051 & 0.083 & 0.032 \\
\hline Shanghai & 0.029 & 0.060 & 0.031 \\
\hline Guangdong & 0.090 & 0.110 & 0.021 \\
\hline & \multicolumn{3}{|c|}{ Offensive } \\
\hline Yunnan & 0.179 & 0.102 & -0.077 \\
\hline Jilin & 0.191 & 0.152 & -0.039 \\
\hline Oinghai & 0.147 & 0.111 & -0.036 \\
\hline Tianjin & 0.061 & 0.042 & -0.018 \\
\hline Inner Mongolia & 0.055 & 0.037 & -0.018 \\
\hline Ningxia & 0.069 & 0.051 & -0.017 \\
\hline Hainan & 0.071 & 0.055 & -0.016 \\
\hline
\end{tabular}

Sources: Authors' own estimates.

\section{Understanding productivity gaps}

Regional productivity performance has important implications for government policymaking at both the national and the regional levels in China. The reduction of income inequality and the improvement of social welfare in less-developed areas depend on improvements in productivity. Economic growth in China in recent decades has been outstanding compared with that of other countries. Key factors underlying this growth are the technological and institutional changes associated with economic reforms initiated in the 1980s. Productivity has also played an important role in effecting these changes. 
As a result, efforts to evaluate China's economic growth have focused on the measurement of productivity in the Chinese economy. There is a large body of studies in this area (Wu 2011). Most authors provided estimates of total factor productivity (TFP) growth and its contribution to economic growth. This study differs from the existing ones by focusing on regional productivity gaps. For this purpose, labour productivity is decomposed into structural, regional and allocative components. The objective is to explore productivity inequality between regions and within zones (coastal, central and western). Labour productivity used in this study is calculated by dividing the industrial output by the number for workers in each sector within the regions.

Labour productivity (LP) at the national level has increased steadily since 2000 regardless of whether gross output or value added is employed in the estimation (Figure 18.2). Across the 20 subsectors covered by this study, however, labour productivity varies considerably. The leading sector is tobacco, followed by communication equipment, ferrous metals, transport equipment and nonferrous metals sectors. There is regional variation also in labour productivity. ${ }^{2}$ In the early years of the sample period (2000-10), Shanghai led the regions with the highest labour productivity followed by Beijing, Tianjin, Guangdong and other coastal provinces. Xinjiang is the only western region where the labour productivity level was above the national average and compatible with the performance of the coastal regions (it was actually ranked number three, just behind Shanghai and Beijing in 2000). In 2005 Tianjin overtook Shanghai to become the leader in terms of labour productivity; however, in 2006, Hainan Island's labour productivity exceeded Tianjin's, and Hainan maintained its number one ranking at the end of the sample period (2010). By 2010, among the top 10 performing regions, seven were coastal provinces (Hainan, Tianjin, Shanghai, Beijing, Liaoning, Shandong and Hebei). Inner Mongolia is the only western region which made it into the top 10, and it benefited mainly from the resource boom in recent decades. Anhui as a central region was ranked number 10. Jilin is a north-eastern province and was in second position in terms of labour productivity performance. The worst-performing region is Ningxia, a western region, with estimated average labour productivity less than half Hainan's in 2010. In general, labour productivity in western regions (except Inner Mongolia and Xinjiang) was lower than the national average during the period 2000-10. Interestingly, the ranking of Guangdong dropped dramatically from number five in 2000 to number 28 in 2010 (just before Ningxia and Shanxi).

2 The estimated values by region, sector and year are not shown due to space constraints. 


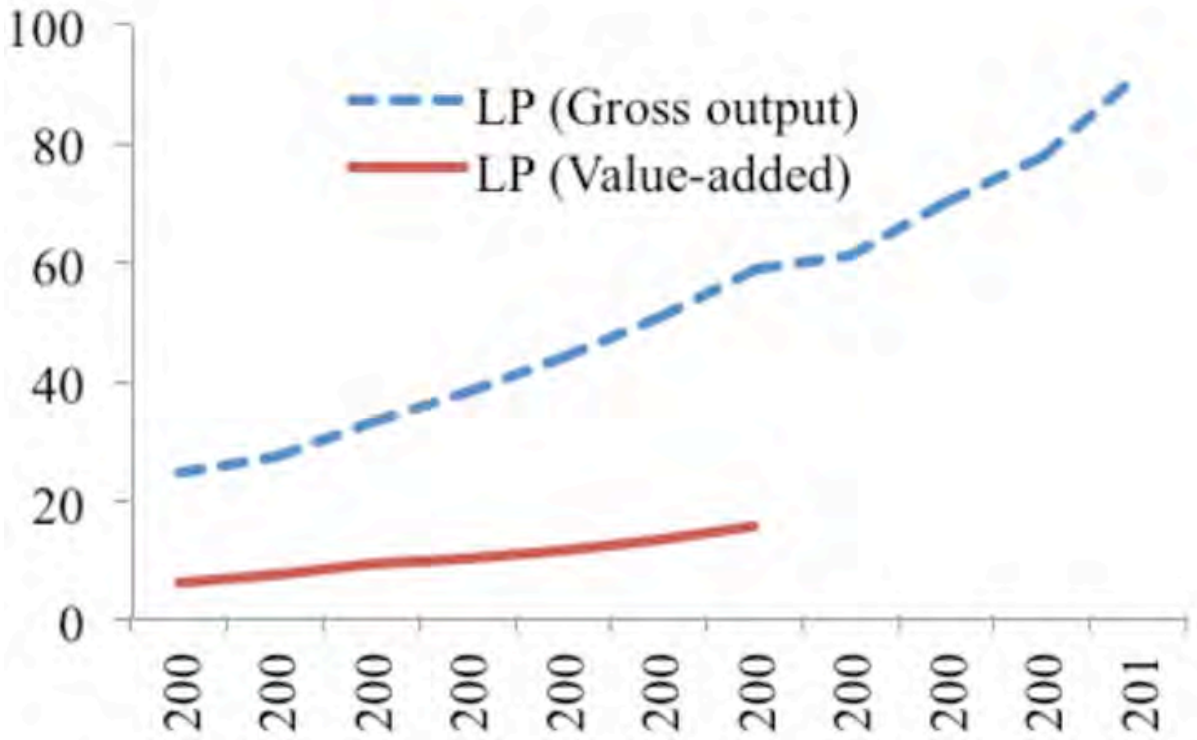

Figure 18.2 Average Labor Productivity in China's Industrial Sector, 2000-10

Source: Authors' calculations. To understand the above-discussed productivity differences, the shiftshare analysis technique is adopted to decompose the productivity gap into several components. For this purpose, the aggregate labour productivity of a region, $X_{r^{\prime}}$ can be expressed as the weighted average of productivity across its sectors. Thus for region $r, X_{r}$ can be written as Equation 18.3.

Equation 18.3

$$
X_{r}=\frac{I_{r}}{L_{r}}=\sum_{i=1}^{n}\left(\frac{I_{i r}}{L_{i r}}\right)\left(\frac{L_{i r}}{L_{i}}\right)
$$

In Equation 18.3 the subscripts $i$ and $r$ denote the $i^{\text {th }}$ industrial sector and the $r^{\text {th }}$ region respectively; $I$ stands for the industrial value added and $L$ for employment. Equation 18.3 states that regional productivity differences can be attributed to two factors. First, differences in labour productivity in the $i$ sectors result in regional disparities in productivity. Therefore, even if there were no regional disparities in each individual sector, regions specialising in more productive sectors would achieve productivity higher than the national average. Second, there are differences in the regional characteristics that have the same influence on productivity in different sectors.

In order to evaluate the relevance of each of these two factors it is necessary to decompose the gap between regional productivity and the national average productivity. According to Esteban (2000), a useful technique for this exercise is the shift-share analysis, which originates from the field of labour economics, and was designed as a technique for analysing growth in regional employment (Benito and Ezcurra 2005). It can, however, be applied to the study of labour 
productivity as well. Following this approach, the productivity gap between a given region and the national average can be decomposed into three components - structural, regional and resource allocation factors.

Let $E_{i, r}$ be sector i's employment share in region $r$ and $E_{i}$ denote sector $i$ 's employment share at the national level. Therefore, $\Sigma E_{i, r}=1$ for all regions, $r$ and $\Sigma E_{i}=1$. Assume $X_{i}$ and $X_{i, r}$ represent labour productivity in sector $i$ and labour productivity sector $i$ in region $r$, respectively. The structural or industry-mix component, $\mu_{r^{\prime}}$ of region $r$ measures the effect on the productivity differential due to the difference between region $r$ 's industrial structure and the national average, assuming that sector productivity in each region is equal to the national average. The structural component can be written as Equation 18.4.

Equation 18.4

$$
\mu_{r}=\sum_{i}\left(E_{i, r}-E_{i}\right) X_{i}
$$

In Equation 18.4, $\mu_{r}$ has a positive value if the region is more specialised in sectors with high labour productivity at the national level and de-specialised in sectors with low labour productivity. $\mu_{r}$ reaches the maximum value if the region specialised in sectors with the highest productivity. Conversely, $\mu_{r}$ would plunge to the minimum if the region had specialised in sectors with the lowest productivity.

The regional or productivity differential component, $\pi_{r^{\prime}}$ is related to the impact of sector-by-sector productivity differences between regional and national average productivity, assuming the region's industrial structure is the same as the national average. The regional component can be written as Equation 18.5 .

\section{Equation 18.5}

$$
\pi_{r}=\sum_{i} E_{i}\left(X_{i, r}-X_{i}\right)
$$

In Equation 18.5, $\pi_{r}$ has a positive value if the region's sector productivity is above the national level.

The allocative component, $\theta_{r^{\prime}}$ is defined as Equation 18.6.

Equation 18.6

$$
\theta_{r}=\sum_{i}\left(E_{i, r}-E_{i}\right)\left(X_{i, r}-X_{i}\right)
$$


In Equation 18.6, $\theta_{r}$ is positive if the region is specialised in sectors which have productivity above the national average. This component is the intersection of the structural and regional components, which may be used as an indicator of the efficiency in allocating resources among the sectors in each region. Given the definitions of the three components, the regional productivity gap can be expressed as Equation 18.7.

\section{Equation 18.7}

$$
G_{r}=X_{r}-X=\mu_{r}+\pi_{r}+\theta_{r}
$$

Equation 18.7 implies that the productivity gap between a region and the national average can be decomposed into three components.

To apply the above-discussed decomposition technique, the average productivity gaps of each region for the period 2000-10 are computed. A summary of the data is presented in Figures 18.3 and 18.4 in which the average gaps for the periods 2000-04 (the first half of the period) and 200610 (the second half) are presented. According to Figure 18.3, nine regions led by Shanghai and Tianjin recorded a positive average productivity gap during 2000-10. The positive gaps on average were much bigger in the second half of the period than in the first half. It is interesting to note that Inner Mongolia changed from a negative gap region to a significantly positive one, while Fijian changed from a positive gap province to a negative one. Furthermore, as expected, the majority of the regions with a positive gap are coastal regions.

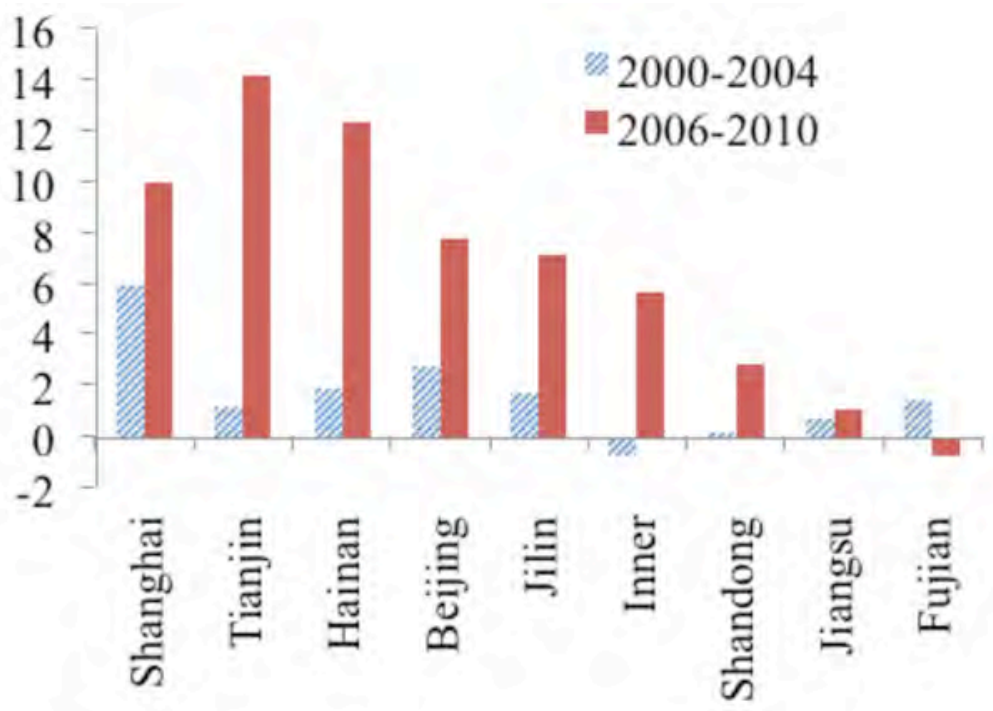

Figure 18.3 Regions with Positive Productivity Gaps

Source: Authors' calculations. 


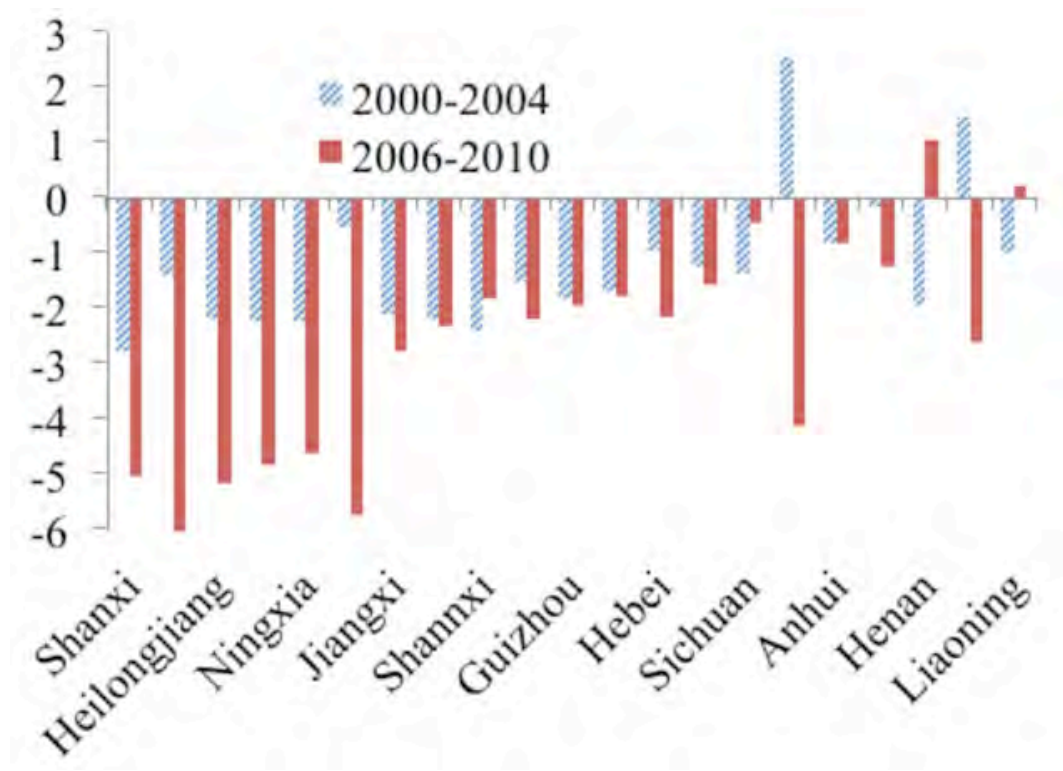

Figure 18.4 Regions with Negative Productivity Gaps

Source: Authors' calculations.

As for the 21 regions with an average negative productivity gap during 2000-10, the regions with the largest gaps are mainly western (Xinjiang, Gansu and Ningxia) and central (Shanxi, Heilongjiang and Jiangxi) regions. Zhejiang is an exception as it is one of the regions with the largest gaps while it is also a relatively developed coastal region (Figure 18.4). The gaps in the second half of the period tend to be bigger than those in the first half. Yunnan and Guangdong moved from a positive position to a negative one while Henan and Liaoning moved in the opposite direction.

The decomposition results show different patterns of productivity gaps among the nine regions with positive gaps. Only three regions (Tianjin, Beijing and Jilin) have achieved allocative efficiency. Shanghai, with the highest productivity gap, has not benefited from allocative efficiency. Hainan and Inner Mongolia also suffered from allocative inefficiency though their productivity is well above the national average. It is also found that Shandong, Jiangsu and Fujian are not specialising in sectors with high productivity.

In the literature on regional disparity, China is often divided into three zones-namely, the coastal: Beijing, Tianjin, Hebei, Liaoning, Shanghai, Jiangsu, Zhejiang, Fujian, Shandong and Guangdong; the central: Shanxi, Jilin, Heilongjiang, Anhui, Henan, Hubei, Hunan and Jiangxi; and the western: Inner Mongolia, Guangxi, Hainan, Chongqing, Sichuan, Guizhou, Yunnan, Shaanxi, Gansu, Qinghai, Ningxia and Xinjiang. It is thus useful to examine 
productivity gaps across the three zones. The estimated results show that while all three zones have had a remarkable growth in labour productivity during the past decade, the central zone's average productivity increased significantly from 2000 to 2005 and the coastal region's average productivity increased dramatically between 2006 and 2010. These increases were driven by good performance in some subsectors. For example, the productivity of the central zone in the smelting and processing of nonferrous metals, and the manufacture of ordinary machinery and transportation equipment, was above the national average in 2005. The productivity of the western zone in the industries of food processing, food manufacturing, beverage manufacturing, petroleum processing and cooking products was above the national average in 2010.

Table 18.6 presents the summary statistics of the productivity gap and its decomposition for the three zones. It is apparent that on average the coastal zone enjoys a small positive productivity gap while the central and western zones show negative gaps. All three zones seem to suffer from allocative inefficiency (negative allocative scores). The coastal zone has labour productivity above the national average while both the central and the western zones have productivity below the national average during 2000-10. Table 18.6 also demonstrates that the coastal zone is not necessarily specialising in sectors with high productivity. On the contrary, the central and western zones may actually specialise in highproductivity sectors according to the same table.

Table 18.6 Summary Statistics of Productivity Gaps by Zone

\begin{tabular}{|l|c|c|c|c|}
\hline Zone & Gap & Structural & Regional & Allocative \\
\hline Coastal & 0.31 & -0.54 & 1.22 & -0.36 \\
\hline Central & -1.31 & 0.13 & -1.34 & -0.10 \\
\hline Western & -1.09 & 1.12 & -1.85 & -0.36 \\
\hline
\end{tabular}

Source: Authors' calculations.

\section{Further analysis of productivity gaps}

In order to determine how much the productivity gap of each component is due to a regional effect or a zonal effect, Equation 18.7 is extended as Equation 18.8 .

Equation 18.8

$$
G_{r}=\mu_{I, r}+\mu_{E, r}+\pi_{I, r}+\pi_{E, r}+\theta_{I, r}+\theta_{E, r}
$$


In Equation 18.8, each of the three productivity gap components (that is, the structural, regional and allocative components) can be expressed as the sum of an internal factor (indicated by the subscript $I$ ) and an external factor (indicated by the subscript $E$ ). The internal factor represents the difference between a particular region and the zone average, while the external factor reflects the difference between the average within the zone and the national mean. The decomposition technique in Equation 18.8 originates from the analysis of income inequality (Lerman 1999). The objective of this section is to examine the contribution of each of the components in Equation 18.8 to total inequality in China's regional productivity differentials. In practice, to accommodate the direct effect and possible indirect impact of each component on national or global $(G)$ productivity gaps, the variance of the regional productivity gap $\left(G_{r}\right)$ is considered and variance decomposition is then adopted. ${ }^{3}$ Accordingly, the global productivity gap is decomposed into six components in a way similar to Equation 18.8; however, due to the use of variance and hence covariance, the contribution of an individual component could have a negative value if the corresponding covariance is negative. In this case, the component in question would exert an offsetting effect on the global productivity gap generated by other components.

As there are six components after decomposition, there are several ways to organise the results. The first set of results is presented in Figure 18.5. Panel 5a shows the percentage shares of the structural, regional and allocative components. It is apparent that the regional component made the dominant contribution to productivity gaps during 2000-10. In recent years this trend seems to have strengthened. It is also shown that the contribution of the structural component has been small and stable over time. In terms of the external (between zone and national means) and internal (between individual province and zone means) factors, their percentage contributing shares are very close, with the external factor share being slightly higher (51 versus 49 on average) (Panel 5b). This finding has important implications. For a long time, policymakers as well as researchers have been concerned mainly with disparity between the zones (coastal, central and western). Regional differences within the zones may be overlooked, and should be addressed. 
Panel 5a

\section{"astructural :Regional = Allocative}

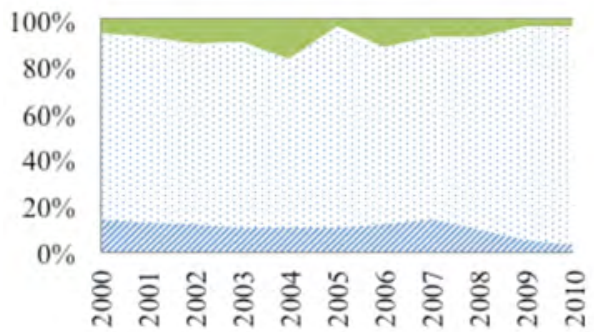

Panel 5b

־External Internal

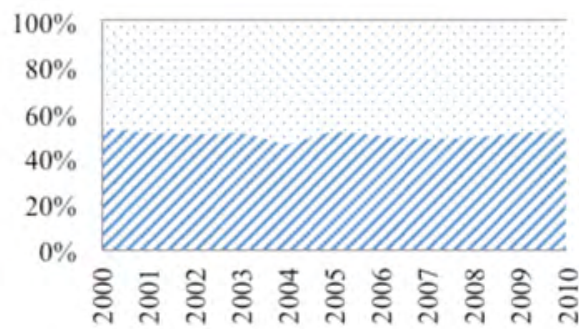

Figure 18.5 Productivity Gap Decomposition, 2000-10

Source: Authors' calculations.

Figure 18.6 shows the composition of the external and internal components. In both cases regional differences are the dominant contributor to productivity gaps. Panel 6a illustrates that the three components (structural, regional and allocative) are relatively stable over time. This is consistent with the observation in Panel 5b of Figure 18.5; however, although the internal factor (Panel 5b of Figure 18.5) may be stable, its three components have changed over time, according to Panel $6 \mathrm{~b}$ of Figure 18.6. Within the zones, regional differences in productivity have increased during 2000-10, particularly in the second half, while the contribution of allocative efficiency and structural components to productivity gaps has declined slightly (Panel 6b).
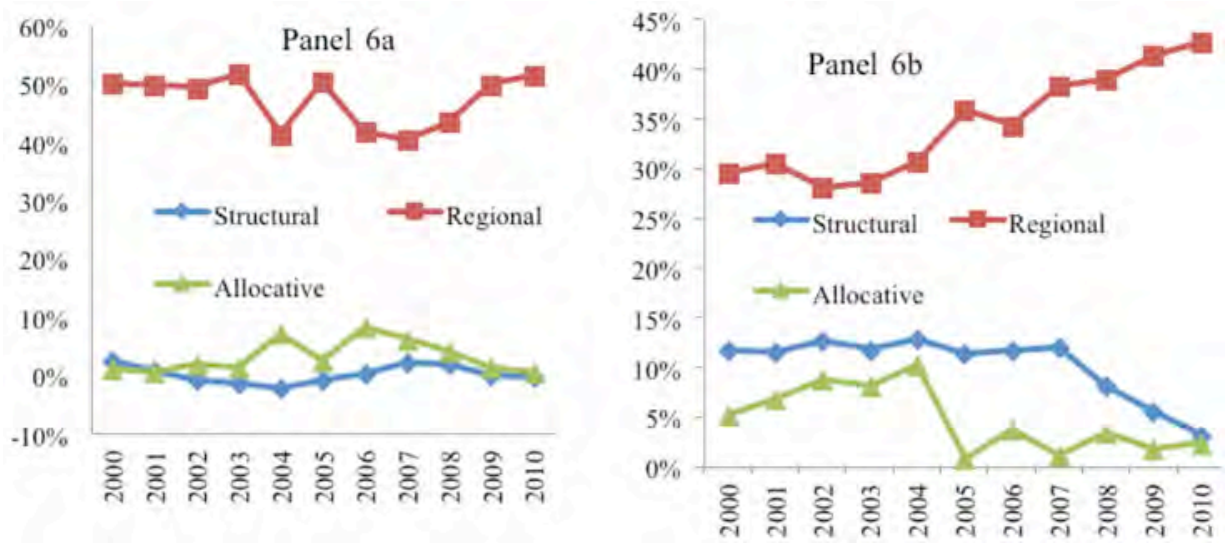

Figure 18.6 Decomposition of External (Panel 6a) and Internal (Panel 6b) Components

Source: Authors' calculations. 
Among the three components, the role of the external and internal factors is not exactly the same. Figure 18.7 shows that the internal factor dominates the structural contribution to productivity gaps. For several years the contribution of the external factor is negative. For regional variation, its contribution is, however, dominated by the external factor and tends to be stable over time. As for allocative efficiency, it was initially dominated by the internal factor and in the second half of the period the external factor took over the dominant role (Figure 18.7).

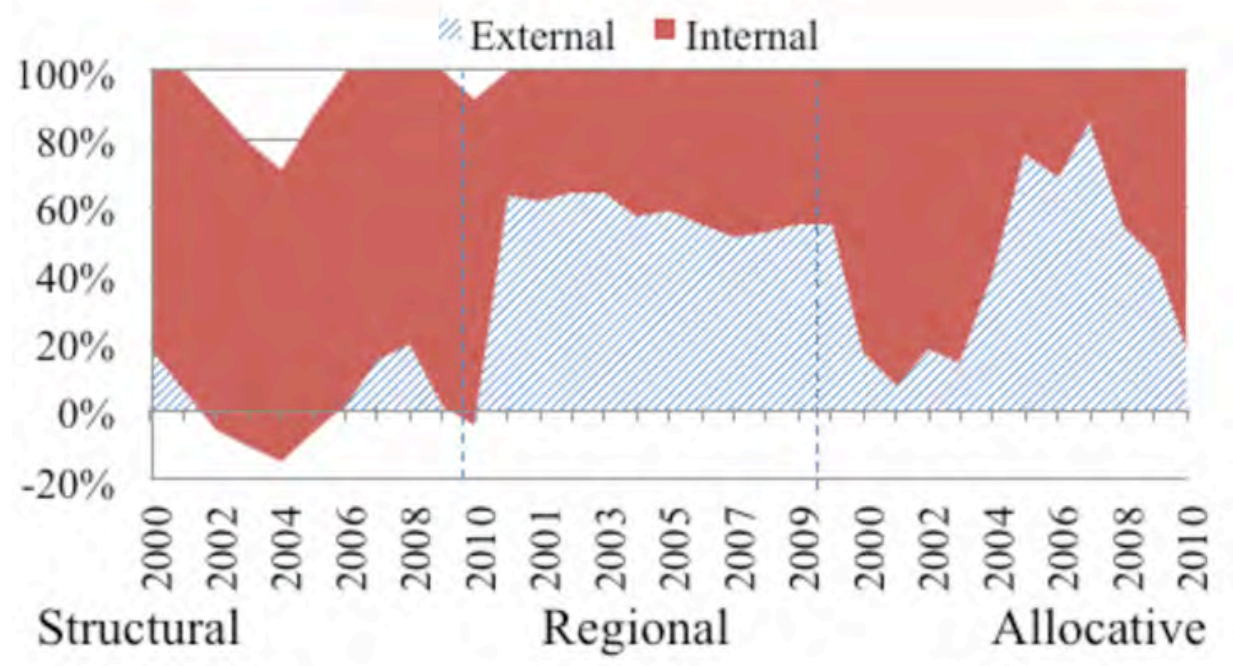

Figure 18.7 Decomposition of the Three Components

Source: Authors' calculations.

\section{Conclusion}

To sum up, using provincial sector-level data during 2000-10, this study examined several issues associated with growth, structural change and productivity gaps in the Chinese manufacturing sector. Overall the country's manufacturing output has been growing rapidly, with the coastal zone growing much faster than the central and western zones. The last two have, however, shown a catch-up in the second half of the period of 2000-10 due to various government policies supporting economic development in these areas. Furthermore, China's manufacturing industry has undergone a great degree of structural change, which also varies between regions. It seems that structural change has accelerated in recent years (in the second half of the 2000s covered by our sample). In addition, the findings in this study show that more coastal 
regions seem to undergo defensive structural change while offensive structural change is more likely to occur in the western regions. There are of course exceptions. Tianjin, for example, is a relatively developed region and it falls into the group with offensive structural change.

As for labour productivity performance across the regions, it is found that growth during 2000-10 was on average impressive. There is, however, considerable regional variation. About one-third of the country's 30 regions recorded a positive productivity gap (relative to the national average). Most of these regions are in the coastal area. Hainan, Jilin and Inner Mongolia are exceptions. Regions with relatively large negative productivity gaps are located mainly in western China. Zhejiang is an exception: it has the sixth-largest negative gap though it is a coastal province. In Yunnan and Guangdong, the productivity gap changed from a large positive one in the first half of the sample period to a large negative one in the second half of the period.

The results of decomposition analysis indicate that the regional component made the greatest contribution to the total productivity gap. This trend seems to have persisted in recent years. Productivity gaps are also attributable to differences within each of the three zones (coastal, central and western) and variation between each zone and the national average. These two seem to be equally responsible for the total productivity gap according to this study. Our estimates also show that disparity within the zones tends to have been worse in recent years while differences between each zone and the national average remain stable.

The findings in this study imply that it is necessary for the Government to formulate province-specific policies. For instance, regions in the central and western zones should focus more on productivity improvement while the coastal zone should focus on structural rationalisation and allocative efficiency. In addition, economic policies should address both inter-zone disparity and intra-zone inequality in productivity. Over the past decade, western region development, the rise of the middle regions and north-eastern reinvigoration programs made significant contributions to the reduction of inter-zone disparity. The central and local governments should also work together to deal with intrazone productivity inequality. 


\section{References}

Abramovitz, M. (1989), Thinking about Growth and Other Essays on Economic Growth and Welfare, Cambridge and New York: Cambridge University Press.

Almon, M. J. and Tang, J. (2011), 'Industrial structural change and the post2000 output and productivity growth slowdown: a Canada-US comparison', International Productivity Monitor 22(1): 44-81.

Bai, C. E., Duan, Y., Tao, Z. and Tong, S. T. (2004), 'Local protectionism and regional specialization: evidence from China's industries', Journal of International Economics 63(2): 397-417.

Benito, J. M. and Ezcurra, R. (2005), 'Spatial disparities in productivity and industry mix: the case of the European regions', European Urban and Regional Studies 12(2): 177-94.

Chen, X. L. and Wu, X. (2003), 'Technological innovation: the basic cause of industrial structural evolution', Lilun Yuekan [Theory Monthly] 12(1): 84-5.

Dong, X., Song, S. and Zhu, H. (2011), 'Industrial structure and economic fluctuation-evidence from China', The Social Science Journal 48(3): 468-77.

Esteban, J. (2000), 'Regional convergence in Europe and the industry mix: a shift-share analysis', Regional Science and Urban Economics 3(3): 353-64.

Fan, C. and Scott, A. (2003), 'Industrial agglomeration and development: a survey of spatial economic issues in East Asia and a statistical analysis of Chinese regions', Economic Geography 79(3): 295-319.

Fiaschi, D. and Lavezzi, A. M. (2007), 'Productivity polarization and sectoral dynamics in European regions', Journal of Macroeconomics 29(3): 612-37.

Havlik, P. (1995), 'Trade reorientation and competitiveness in CEECs', in R. Dobrinsky and M. Landesman (eds), Transforming Economies and European Integration, 141-62, Aldershot, UK: Edward Elgar.

Jefferson, G. H., Rawski, T. G. and Zhang, Y. (2008), 'Productivity growth and convergence across China's industrial economy', Journal of Chinese Economic and Business Studies 6(2): 121-40.

Kallioras, D. and Petrakos, G. (2010), 'Industrial growth, economic integration and structural change: evidence from the EU new member-states regions', The Annals of Regional Science 45(3): 667-80. 
Lemoine, F., Mayo, G., Poncet, S. and Ünal, D. (2014), The geographic pattern of China's growth and convergence within industry, Working Paper No. 2014-04, CEPII Research Center, Paris.

Lerman, R. I. (1999), 'How do income sources affect income inequality', in J. Silber (ed.), Handbook of Income Inequality Measurement, 341-62, Boston: Kluwer Academic.

Li, Z. and Long, F. (2001), Study on Industrial Economy in China. Chengdu: Southwest Financial University Press.

Lin, H. L, Li, H. Y. and Yang, C. H. (2011), 'Agglomeration and productivity: firm-level evidence from China's textile industry', China Economic Review 22 (3): 313-29.

Marti, L., Rosa, P. and Fernandez, J. I. (2011), 'Industrial productivity and convergence in Chinese regions: the effects of entering the World Trade Organisation', Journal of Asian Economics 22(2): 128-41.

National Bureau of Statistics (NBS) (various years), China Statistical Yearbook, Beijing: China Statistics Press.

National Bureau of Statistics (NBS) (various years), China Statistical Yearbook of Industrial Economy, Beijing: China Statistics Press.

O'Callaghan, B. A. and Yue, G. (2000), 'An analysis of structural change in China using biproportional methods', Economic Systems Research 12(1): 99-111.

Peng, L. and Hong, Y. (2013), 'Productivity spillovers among linked sectors', China Economic Review 25: 44-61.

Rizov, M. and Zhang, X. (2014), 'Regional disparities and productivity in China: evidence from manufacturing micro data', Papers in Regional Sciences.

Timmer, M. P. and Szirmai, A. (2000), 'Productivity growth in Asian manufacturing: the structural bonus hypothesis examined', Structural Change and Economic Dynamics 11: 371-92.

Wang, L. and Szirmai, A. (2013), 'The unexpected convergence of regional productivity in Chinese industry, 1978-2005', Oxford Development Studies 41(1): 29-53.

Wei, Y. H. (2000), Regional Development in China: States, Globalization, and Inequality, London: Routledge. 
Deepening Reform for China's Long-Term Growth and Development

Wen, M. (2004), 'Relocation and agglomeration of Chinese Industry', Journal of Development Economics 73(1): 329-47.

Wu, Y. (2011), 'Total factor productivity growth in China: a review', Journal of Chinese Economic and Business Studies 9(2): 111-26.

$\mathrm{Xu}, \mathrm{X}$. and Voon, J. P. (2003), 'Regional integration in China: a statistical model', Economic Letters 79(1): 35-42.

Zhang, Q. and Felmingham, B. (2002), 'The role of FDI, exports and spillover effects in the regional development of China', Journal of Development Studies 38(4): 157-78. 
This text taken from Deepening reform for China's long-term growth and development, edited by Ligang Song, Ross Garnaut, Cai Fang, published July 2014 by ANU Press, The Australian National University, Canberra, Australia. 